\title{
A administração pública e a educação ambiental no Programa de Gestão Integrada de Resíduos Sólidos: uma reflexão de uma experiência local
}

\section{Public Administration and Environmental Education in the Program of Integrated Management of Solid Residues: a reflection about a local experience}

\author{
Jane Eyre G. Vieira* \\ Agustina Rosa Echeverría**
}

\section{Resumo}

Este artigo discute o Programa de Gestão Integrada de Resíduos Sólidos (PGIRS), a partir de uma experiência em Quirinópolis (Goiás) e do acompanhamento da Caixa Econômica Federal, propondo a educação ambiental como estratégia para ampliar a obtenção de resultados. O PGIRS, do governo federal, pretendeu contribuir com a administração pública municipal na solução dos problemas ambientais gerados pelo lixo urbano e promover a participação dos atores locais na implementação do mesmo, apresentando, contudo, limitações para atingir seus objetivos.

Palavras-chave: administração pública; educação ambiental; sustentabilidade; desenvolvimento urbano.

Abstract

This study discusses the Program for the Integrated Management of Solid Residues (PGIRS) starting from an experience in Quirinópolis (Goiás), which was accompanied by Caixa Econômica Federal. It proposes Environmental Education as a strategy for improving results. The PGIRS Brazilian Federal Government's aims at contributing to the Public Administration of the Municipality in its efforts to solve environmental problems generated by urban waste. It also hopes to promote the participation of local agents in setting up the program, while at the same time, presenting the limitations involved in carrying it out.

Key words: public administration; environmental education; sustainability; urban development.

\footnotetext{
Doutora em Ciências Ambientais - Ciamb (UFG). Assistente social, especialista em planejamento urbano e ambiental pela UCG. Analista técnica social sênior da Caixa Econômica Federal na Gerência de Apoio ao Desenvolvimento Urbano de Goiás. Endereço Rua 11, n 250, Centro - Goiânia/G) - Brasil - CEP: $74015-170$ E-mail: jane.vieira@caixa.gov.br.

* Doutora em educação. Bacharel, licenciada e mestre em química. Professora-pesquisadora do Instituto de Química da Universidade Federal de Goiás e do Programa de Doutorado em Ciências Ambientais - Ciamb (UFG). Endereço: Universidade Federal de Goiás - Instituto de Química. Campus II. Samambaia. Caixa Postal 131 Goiânia/Goiás - Brasil - CEP 74001-970.

E-mail: agustina@quimica.ufg.br.

Artigo recebido em julho de 2005 e aceito para publicação em julho de 2006
} 


\section{Introdução}

No Brasil pouco se avalia os resultados alcançados por programas de desenvolvimento urbano com vistas a corrigir suas distorções e reorientar as ações para a busca da efetividade de resultados.

Das poucas iniciativas de avaliação, podemos mencionar uma do Conselho Curador do FGTS, ${ }^{1}$ em 1999, que contratou o Departamento de Arquitetura e Urbanismo da Escola de Engenharia de São Carlos (EESC) da USP, para elaborar uma metodologia de avaliação dos programas de habitação e saneamento financiados com recursos do FGTS. Outra iniciativa, em 2002, foi uma pesquisa, realizada pelo Instituto Materno Infantil (Imip) e a Fundação Osvaldo Cruz (Fiocruz), em parceria com a Fundação Nacional de Saúde (Funasa). Nesse estudo foram analisados os investimentos em saneamento no Brasil, no período entre 1996 e 2000, com relação aos impactos na saúde e no Sistema Único de Saúde (SUS) decorrentes dos agravos relacionados ao saneamento ambiental inadequado.

Sem a pretensão, no momento, de suprir essa carência de avaliação de resultados alcançados com tais programas, este artigo tem como objetivo avançar na discussão do Programa de Gestão Integrada de Resíduos Sólidos (PGIRS), refletindo de forma crítica suas potencialidades e deficiências e sinalizar ações para a melhoria do desempenho dos atuais programas de saneamento dessa natureza.

O programa em questão propiciou aos municípios o financiamento de um rol de estudos e projetos, os quais pretendem solucionar de forma integrada a problemática socioambiental gerada pelos resíduos descartados pela população urbana. Contudo, apresentou limitações quanto à capacitação administrativa e técnica das administrações públicas municipais para sua implementação, reduzindo a efetividade dos resultados que poderiam ser alcançados com a aplicação dos recursos alocados.

A primeira parte deste artigo apresenta o PGIRS e as intervenções propostas nos editais do seu gestor, o Fundo Nacional do Meio Ambiente (FNMA), bem como a atuação operacional e técnica da Caixa Econômica Federal (Caixa), no programa. Aborda-se o papel da Caixa, na sua área de desenvolvimento urbano, por meio das gerências regionais de Desenvolvimento Urbano (Gidur), com o acompanhamento técnico dos programas pelas equipes multidisciplinares, da qual uma das pesquisadoras, autora deste artigo, faz parte.

Os dados utilizados neste artigo foram obtidos no âmbito do acompanhamento técnico do PGIRS, pela Caixa, tanto dos seus arquivos quanto da atuação da autora como analista técnica social, responsável pelo acompanhamento do programa no município em estudo.

Em seguida é apresentada uma reflexão sobre a educação ambiental (EA), que se configura como um componente do programa, conforme os editais, embora nesses editais não haja orientação quanto à metodologia e intensidade na execução das ações de EA no PGIRS. É discutida a importância da definição do modelo teórico da abordagem em EA no programa, sendo retomada ao final do artigo, definindo-a como pressuposto para a formação de administradores públicos e cidadãos para a gestão ambiental da cidade, especialmente, para a gestão integrada dos resíduos sólidos.

\section{Contextualização do PGIRS do FNMA}

O PGIRS, também denominado Programa Brasil Joga Limpo, foi criado pelo Ministério do Meio Ambiente por meio da ação Projetos Demonstrativos Visando a Gestão Integrada de Resíduos Sólidos e Saneamento Ambiental (BRASIL, MMA, 2004). Esse programa teve como gestor o FNMA e como agente operador a Caixa Econômica Federal.

\footnotetext{
${ }^{1}$ FGTS - Fundo de Garantia por Tempo de Serviço; OGU - Orçamento Geral da União; FAT - Fundo de Amparo ao Trabalhador; BID - Banco Interamericano de Desenvolvimento e BIRD - Banco Internacional de Reconstrução e Desenvolvimento.
} 
Entre os anos de 2000 e 2001, o FNMA lançou três editais para seleção de propostas que foram apresentadas por municípios com população urbana entre 20.000 e 100.000 habitantes (Edital FNMA nº 6/2000, Edital FNMA nํㅗ 5/2001 e Edital FNMA nº 12/2001).

Os recursos foram disponibilizados pelo FNMA, oriundos de um fundo que tem participação do Orçamento Geral da União e demais organismos, inclusive internacionais, que são repassados ao município por intermédio da Caixa, por meio de contratos firmados e liberados à proporção que as metas contratadas são executadas.

O programa foi concebido visando servir de suporte para as soluções de uma das questões que têm afetado o meio ambiente, qual seja, a degradação promovida pela ação antrópica de populações urbanas. Todas as ações que fazem parte da proposta, presentes nos editais e nos projetos apresentados, são requisitos para o alcance de resultados positivos pelo programa, portanto, itens que fazem parte das metas que são acompanhadas, orientadas e avaliadas pela equipe técnica multidisciplinar da Caixa junto ao agente executor.

\section{Intervenções inerentes ao PGIRS}

As principais ações que fazem parte das intervenções previstas no PGIRS, presentes em um ou mais dos editais (na primeira e na segunda chamadas), incluem a instalação do Fórum Municipal Lixo e Cidadania como requisito para o programa; a mobilização da sociedade organizada para o seu acompanhamento e participação nas decisões sobre o gerenciamento dos resíduos urbanos; a construção de aterro sanitário com tecnologia adequada para a disposição dos resíduos urbanos e a elaboração do Plano de Gestão Integrada de Resíduos Sólidos contendo em seu bojo estudos, projetos e relatórios. Esse plano inclui o Programa de Educação Ambiental (EA) junto aos munícipes e o plano social para as famílias que sobrevivem da coleta de materiais recicláveis - catadores das ruas e dos lixões -, prevendo sua inclusão social, inclusive a retirada das crianças do Lixo. O PGIRS, que está vinculado ao programa Criança no Lixo Nunca Mais, da Unicef, foi também denominado Brasil Joga Limpo. O plano social enfatiza o apoio à organização desses trabalhadores como categoria, por meio de associações ou cooperativas dos catadores de materiais recicláveis.

Está previsto, também como parte do PGIRS, o estudo dos compostos sólidos e orgânicos e da sua comercialização, a avaliação dos impactos do empreendimento e das áreas degradadas pelos lixões (com proposição de medidas mitigadoras) e a formulação de instrumentos legais específicos para a área de resíduos sólidos.

Os diversos planos estão previstos na chamada I do edital, enquanto sua execução geralmente é prevista na chamada II, como é o caso do plano de recuperação das áreas degradadas por lixões, o plano para reciclagem de materiais inorgânicos, para a realização da compostagem dos resíduos orgânicos e o Plano para a Universalização dos Serviços de Limpeza Urbana.

Outra importante ação prevista é a qualificação dos gestores, técnicos e servidores da limpeza urbana em todos os níveis e a qualificação profissional dos catadores de materiais recicláveis.

\section{Atuação da Caixa Econômica Federal no PGIRS}

A Caixa, operadora do programa e contratada para prestação de serviços ao MMA/FNMA, atua na sua área de desenvolvimento urbano por meio das gerências regionais, tendo a sua missão como elemento norteador:

Promover a melhoria contínua da qualidade de vida da sociedade, intermediando recursos e negócios financeiros de qualquer natureza, atuando, prioritariamente, no fomento ao desenvolvimento urbano e nos segmentos de habitação, saneamento e infra-estrutura, e na administração de fundos, programas e serviços de caráter social. (CAIXA, 2004)

Segundo estudo de análise dos investimentos em saneamento no Brasil no período 1996-2000, realizada pela Fiocruz em 2002, a partir de 1996, por intermédio da Secretaria de Desenvolvimento Urbano (Sedu) da Presidência da República, atual Ministério das Cidades, o governo federal "passa a utilizar a Caixa como agente financeiro, o que parece indicar uma maior racionalidade na aplicação dos recursos". Esse estudo aponta que, ao longo da década de 1990, houve uma redução das aplicações dos recursos do FGTS e uma política de privatiza- 
ção proposta pelo governo federal, conduzida pelo Programa de Modernização do Setor Saneamento, (BRASIL, 1999 apud FIOCRUZ, 2002, p.79). Nesse sentido uma parcela maior de recursos da União passou a ser utilizada no setor de saneamento, sendo:

importante avaliar os impactos que esta política causou, na medida em que produziu alterações nos mecanismos e nas ações financiadas. O aumento da participação dos recursos do Orçamento Geral da União é, em grande parte, decorrente da redução dos recursos do FGTS, determinado pelos acordos com o FMI. (FIOCRUZ, 2002 p.79)

A Caixa possui, em cada estado da Federação, uma Gerência de Apoio ao Desenvolvimento Urbano (Gidur) com equipe administrativa, técnica e operacional. A equipe técnica é composta por profissionais com formação em engenharia, arquitetura, serviço social, sociologia, pedagogia, psicologia, direito, economia e afins que verifica a viabilidade física e socioambiental dos projetos apresentados, vinculados aos programas de Desenvolvimento Urbano (PDU). Essa equipe promove a análise, o acompanhamento e a avaliação técnica dos empreendimentos propostos pelos agentes operadores, estados, municípios e seus intervenientes executores. Mediante resultado dessas análises, a Caixa repassa os recursos financeiros de diversas origens (FGTS, OGU, FAT, Caixa ou organismos multilaterais), ${ }^{2}$ após execução das metas contratadas no projeto físico e de trabalho social.

No caso do PGIRS, após a seleção inicial no FNMA, os projetos específicos e os produtos contratados são submetidos à avaliação da equipe multidisciplinar, que além das ações citadas, promove visitas e reuniões para acompanhamento e orientação dos projetos desenvolvidos pelo município contratado, desempenhando importante papel de contribuição para a correta aplicação dos recursos públicos vinculados ao programa e para a efetividade dos resultados alcançados.

Assim como no PGIRS, a Caixa acompanha muitos outros programas de desenvolvimento urbano, desde a apresentação dos projetos até sua execução e avaliação. Nestes são desenvolvidas, em diferentes níveis de intensidade, as ações de educação ambiental junto aos beneficiários, como um dos elementos que contribui para a sustentabilidade ambiental dos empreendimentos implantados. São programas vinculados ao Ministério das Cidades, ao Ministério do Meio Ambiente e a outros gestores, com ações voltadas para a habitação popular, esgotamento sanitário, abastecimento de água, tratamento de água e esgotos, drenagem urbana, e resíduos sólidos urbanos.

Desses programas destacam-se o Programa de Subsídio à Habitação (PSH), o Habitar Brasil BID, o de Habitação de Interesse Social, o Imóvel na Planta - FGTS, o Crédito Solidário, o Programa de Arrendamento(PAR), o de Saneamento Ambiental Urbano, o de Fortalecimento da Gestão Urbana, o de Reabilitação de Áreas Urbanas Centrais, o de Regularização Fundiária e o de Resíduos Sólidos Urbanos.

\section{Compromisso da Caixa e dos seus profissionais com os princípios ético-ambientais}

Os princípios que regem o trabalho técnico estão explícitos nos normativos da Caixa para a operação de cada programa, além daqueles implícitos, presentes na atuação de vários de seus profissionais, pautados no paradigma ambiental, construídos com base em uma nova ética - a ética multidimensional.

Uma proposta alternativa diz respeito a uma ética multidimensional (ou ambiental), em que um novo homem, ciente do seu propósito na teia da vida e de que ele é parte indissolúvel do meio ambiente, mantém relações dialogais com os seus semelhantes, com a natureza, com os outros seres vivos e com o mundo. Esta ética baseada em novos valores de cooperação, de qualidade, de participação e de integração considera a vida em todas as suas dimensões. (ANDRADE, 2001, p.97)

Os PDU incorporam os conceitos de habitabilidade e sustentabilidade ambiental, advindos de acordos internacionais do quais o Brasil é signatário, como Agenda Habitat e (Istambul, 1996) e Eco (Rio 92), entre outros, e prevêem a participação comunitária das populações diretamente interessadas.

\footnotetext{
${ }^{2}$ FGTS - Fundo de Garantia por Tempo de Serviço; OGU - Orçamento Geral da União; FAT - Fundo de Amparo ao Trabalhador; BID Banco Interamericano de Desenvolvimento e BIRD - Banco Internacional de Reconstrução e Desenvolvimento.
} 
Aceita-se que exista uma tendência, atual e irreversível, de passagem das macropolíticas, dos grandes projetos de desenvolvimento como forma predominante, para uma crescente participação das micropolíticas e dos pequenos projetos que levarão à definição e constituição de múltiplos modelos e múltiplas formas de inserção de cada conjunto no processo geral de transformações. (BECKER, 1999, p.63-64).

É nesse marco que se imagina uma participação ativa e direta das populações locais, entendendo a sustentabilidade como projeto alternativo de desenvolvimento. Não se propõe uma idéia de sustentabilidade baseada simplesmente na racionalização de recursos, mas uma combinação das diferentes dimensões da vida humana: econômica, sociológica, política, cultural, tecnológica, ambiental, ética e estética.

Tanto o Ministério do Meio Ambiente como a Caixa são signatários do Protocolo Verde, que incorpora a variável ambiental na gestão e a concessão de crédito oficial e benefícios fiscais. Essa ação do governo federal visa buscar mecanismos que evitem a utilização de créditos oficiais e benefícios fiscais em atividades que sejam prejudiciais ao meio ambiente.

Cabe ao poder público e à coletividade defender e preservar o meio ambiente, conforme a Lei no 6.938 de 31 de agosto de 1981, que institui a Política Nacional de Meio Ambiente, dispondo em seu artigo 12, que as entidades e órgãos de financiamento e incentivos governamentais "condicionarão a aprovação de projetos habilitados a esses benefícios ao licenciamento, na forma da Lei, e ao cumprimento das normas, dos critérios e dos padrões expedidos pelo Conama."

\section{Importância da definição de uma abordagem de educação ambiental}

Embora a educação ambiental esteja prevista no Programa de Gestão Integrada de Resíduos Sólidos, não há uma orientação do gestor quanto à metodologia, grau de intensidade e a orientações teóricas e filosóficas para a sua implementação, ficando restrita à sua solicitação na proposta do município a ser encaminhada ao FNMA.

Para a execução do PGIRS, faz-se necessária a implementação, no município, da EA em todos os níveis e em seus aspectos formal e informal. O público-alvo inicial deveria ser os gestores públicos, a serem sensibilizados em relação às questões ambientais vinculadas à temática, aos aspectos físico e social, à compreensão da importância da inter-relação das ações a serem empreendidas e à necessidade de busca da participação de todo cidadão na gestão dos resíduos sólidos urbanos, implicando a EA junto a todos os segmentos da população.

A gestão ambiental deve partir do entendimento de ambiente como uma categoria sociológica, e não apenas biológica como os enfoques sistêmicos das ciências modernas presumem. Segundo Leff,

O ambiente é integrado por processos, tanto de ordem física como social, dominados e excluídos pela racionalidade econômica: a natureza superexplorada e a degradação socioambiental, a perda de diversidade biológica e cultural, a pobreza associada à destruição do patrimônio de recursos dos povos e à dissolução de suas identidades étnicas, a desigual distribuição dos custos ecológicos do crescimento e a deterioração da qualidade de vida. Ao mesmo tempo, o ambiente surge como um novo potencial produtivo, resultado da articulação de processos de ordem natural e social que mobilizam a produtividade ecológica, a inovação tecnológica e a organização cultural. (LEFF, 2001, p.224).

O modelo teórico proposto para o desenvolvimento da EA, embora não previsto nos editais do FNMA e nem sempre abordado pelos municípios nos planos/projetos enviados para análise da Caixa, deveria, para alcançar resultados efetivos, alinhar-se a um modelo educacional de interação com as diversas abordagens pedagógicas da educação, na busca pela ampliação das possibilidades de envolvimento do cidadão na questão ambiental posta. Teria de contribuir, também, para a percepção de sua responsabilidade e condição de atuação individual e coletiva na gestão ambiental, no caso, na gestão dos resíduos sólidos urbanos.

Gestão ambiental, portanto, é vista aqui como o processo de mediação de interesses e conflitos (potenciais ou explícitos) entre atores sociais que agem sobre os meios físico-natural e construído, objeti- 
vando garantir o direito ao meio ambiente ecologicamente equilibrado, conforme determina a Constituição Federal. (QUINTAS, 2001, p.146)

Segundo Mininni-Medina (2001), a visão socioambiental trabalha a relação ser humano/natureza reintegrando o homem na natureza, como espécie biológica, carregando características específicas. O meio Ambiente "se gera e constrói no processo histórico das inter-relações entre sociedade e natureza". Nessa vertente percebem-se os problemas ambientais de forma crítica, buscando determinar suas causas reais e não somente os efeitos gerados.

Com relação à construção do conhecimento nessa abordagem socioambiental da educação ambiental, a autora relaciona que:

Não existe uma teoria do conhecimento explícita; o fundamento epistemológico da Educação Ambiental deve ser aprofundado no confronto com a própria experiência e com as reflexões dos epistemólogos a respeito; coloca ênfase nas inter-relações histórico-sociais e no conhecimento científico, como construção social da humanidade (sócio gênesis, psicogênesis); resgata e valoriza o conhecimento e a experiência tradicional e popular; assinala o papel fundamental da interdisciplinaridade em nível das ciências. (MININNI-MEDINA, 2001, p. 63)

Ainda com relação à EA na vertente socioambiental, no que diz respeito à visão do papel da educação, esta privilegia os aspectos formais e não-formais da educação na perspectiva de que ambos são complementares. Visa à plena realização do ser humano na sua dimensão biopsicossocial e concebe a educação de caráter permanente e orientada para o futuro, preocupando-se com a construção de valores e conhecimentos para a tomada de decisões adequadas à preservação do ambiente e da própria sociedade humana.

A interdisciplinaridade é requisito e ponto de referência constante nos projetos educacionais dos programas de formação ambiental. Segundo Leff (2001), a interdisciplinaridade não é o somatório nem a articulação de disciplinas, mas também não ocorre à margem delas. Ela requer que se avance na construção de novos objetos interdisciplinares de estudo, por meio do questionamento dos paradigmas dominantes, da formação dos professores e da incorporação do saber ambiental emergente aos novos programas curriculares.

A EA na formação dos gestores públicos e da população passa a ser uma estratégia da administração pública na execução do PGIRS, por meio do sistema educacional formal, como nos projetos de educação não-formal nas comunidades, onde se dá, de acordo com Leff (2001), a politização dos valores ambientais, a apropriação social da natureza e a autogestão de seus recursos de produção. Para o autor,

Os desafios do desenvolvimento sustentável implicam a necessidade de formar capacidades para orientar um desenvolvimento fundado em bases ecológicas, de equidade social, diversidade cultural e democracia participativa. Isto estabelece o direito à educação, à capacitação e à formação ambiental como fundamentos da sustentabilidade, que permita a cada pessoa e cada sociedade produzir e apropriar-se de saberes, técnicas e conhecimentos para participar na gestão de seus processos de produção, decidir sobre suas condições de existência e definir sua qualidade de vida. Isto permitirá romper a dependência e iniqüidade, fundadas na distribuição desigual do conhecimento, e promover um processo no qual os cidadãos, os povos e as comunidades possam intervir a partir de seus saberes e capacidades próprias nos processos de decisão e gestão do desenvolvimento sustentável. (LEFF, 2001, p. 246)

\section{Uma experiência do PGIRS no município de Quirinópolis (Goiás)}

O município de Quirinópolis apresentou proposta ao FNMA para o PGIRS, atendendo ao Edital no 5/2001, cuja elaboração se deu por meio de uma consultoria contratada pela administração municipal, contemplando todas as exigências contidas naquele edital, sendo uma das aprovadas pela câmara técnica do fundo e encaminhada para contratação, orientação e acompanhamento técnico e operacional da Caixa no município. 
Quirinópolis situa-se no sudoeste de Goiás, tendo uma área de $3.792 \mathrm{~km}^{2}$ e área urbana de $100 \mathrm{~km}^{2}$. Tem como coordenadas geográficas latitude $18^{\circ} 26^{\prime} 54^{\prime \prime}$ e longitude $50^{\circ} 27^{\prime} 06^{\prime}$ '. Encontra-se a uma distância de $500 \mathrm{~km}$ de Brasília/DF e a $300 \mathrm{~km}$ da capital, Goiânia, sendo uma região agrícola, forte produtora de grãos (soja, milho, algodão, sorgo etc.). De acordo com o censo IBGE (2000), a população do município era de 36.511 habitantes, $85 \%$ dos quais moradores da zona urbana.

As ações propostas pelo município ao FNMA, na modalidade de primeira chamada, contemplaram: elaboração do PGIRS, com vários estudos e planos; construção do aterro sanitário; plano de recuperação das áreas degradadas; elaboração e implantação do Programa de Educação Ambiental; elaboração e implementação do plano social junto aos catadores, inclusive apoio à sua organização e inserção social das famílias que sobrevivem do lixo; construção de pequeno galpão de triagem; elaboração e implantação do Programa de Qualificação Profissional; formulação de instrumentos legais específicos na temática de resíduos sólidos; realização de estudos de viabilidade técnico-econômica da reciclagem dos resíduos sólidos, da compostagem de resíduos orgânicos e do reaproveitamento e disposição final de entulhos; elaboração de plano de gerenciamento para os resíduos do serviço de saúde; estudo/estimativa da quantidade e da composição do lixo gerado no município; e Plano de Universalização dos Serviços de Limpeza Urbana, incluindo implantação de campanhas informativas sobre horário de coleta e elaboração de plano de otimização de rota para varrição, coleta e transporte dos resíduos sólidos urbanos.

Na forma como a proposta foi elaborada, os gestores e corpo técnico do município, com poucas exceções, não se apropriaram do seu conteúdo e das necessidades do município que a justificasse. Assim, desconheciam praticamente todos os itens da proposta apresentada e selecionada pelo FNMA.

A proposta foi apresentada ao FNMA, desprovida de uma prévia e intensa discussão dos problemas e das possíveis soluções que orientassem a gestão integrada dos resíduos sólidos no município; ou seja, foi elaborada por uma consultoria para atender aos requisitos do edital, e após a aprovação, não passava de uma quantidade considerável de papéis sem o conhecimento dos gestores e lideranças. A proposta carecia de equipes locais para a sua execução. Faltava a qualificação dos gestores e técnicos locais, ficando a mesma carente de defensores e, mesmo, de conhecedores das proposições formuladas, notadamente, no campo dos trabalhos relacionados às ações socioeducativas junto à comunidade em geral.

A proposta não contava, ainda, com a disseminação do seu conteúdo junto aos parceiros nela relacionados e junto ao próprio corpo gestor e técnico da prefeitura.

A EA junto aos munícipes e o trabalho social especificamente com os catadores foram tratados pelos técnicos da prefeitura (engenharia e saneamento) como um desafio impossível de ser enfrentado. Afirmava-se que não havia profissionais capacitados para o desempenho da tarefa, o que consumiu um ano de orientações e solicitações dos técnicos sociais e da gerência da Gidur/Caixa, sem o devido atendimento ao proposto.

Somente após esforço institucional da Caixa junto ao município foi possível garantir ações nessa direção, mesmo que com menor intensidade em relação à proposta inicial, mas o possível de se executar com o quadro político/institucional/técnico existente no município, que mesmo com a presença de uma universidade estadual na área, não contava com articulação suficiente para parcerias, por razões que não serão tratadas neste artigo.

Parcerias pontuais aconteceram durante a fase que precedeu à execução das ações de EA. A convite da universidade local foi realizada palestra pela técnica social da Caixa, na Semana do Meio Ambiente em 2002. Esta envolveu os técnicos da prefeitura na apresentação e divulgação da proposta em início, desenvolvendo conteúdo sobre a EA direcionada para o PGIRS.

Um exemplo de falta de articulação local se deu após a aprovação pelo FNMA, já na fase inicial de execução do projeto, em reunião solicitada pela Caixa com os parceiros para obtenção de informação destes quanto à proposta por eles apresentada. A equipe da CAIXA deparou-se com o desconhecimento pelos que foram apontados como parceiros, não só do seu possível papel a ser desempenhado na parceria, como da proposta em si. O fato evidenciou a necessidade de um trabalho diferenciado dos técnicos da Caixa, que ao invés de acompanhamento da evolução das discussões locais, passou para a divulgação e fomento da discussão sobre a proposta em 
andamento, que por requisito haveria de obter a participação de todos nas decisões e encaminhamentos a serem observados.

A realização do Fórum Municipal Lixo e Cidadania, promovido anteriormente para atender ao requisito do programa, foi retomada por orientação técnica da Caixa. O encontro visa ser um espaço aberto à comunidade para os debates das questões relacionadas ao lixo urbano e a sua gestão. Contudo, o fórum no município em questão foi organizado e desenvolvido apenas com palestras e sem espaço garantido para discussões e proposições dos diversos participantes, contudo, atingindo o objetivo de tornar transparentes para a sociedade as ações empreendidas.

A proposta resgatada do plano apresentado ao FNMA que prosperou sob a orientação técnica da Caixa, em termos de formação na temática de EA, foi direcionada e realizada junto aos segmentos multiplicadores, sendo estes considerados reeditores de EA. Reeditores nesse caso pelo fato de não serem meros multiplicadores, mas por terem um público-alvo próprio e serem capazes de reeditar, ou seja, assimilar, adaptar e transmitir os conteúdos.

\section{Métodos e técnicas utilizadas na execução do PGIRS em Quirinópolis (Goiás)}

As ações socioeducativas do programa foram sistematizadas no projeto de trabalho social. No aspecto da EA foi acordado entre a equipe da Caixa e o município um conjunto de ações possíveis para o primeiro momento do PGIRS, por estar ainda na primeira chamada do edital, ou seja, ter alocado recursos para ações, como planos e estudos, além da construção do aterro, cuja etapa concluída qualificaria o município a pleitear mais recursos ao FNMA.

Assim, utilizou-se, como técnica para alcance dos objetivos do programa, a formação de multiplicadores/reeditores de EA. O objetivo foi qualificar pessoas que viessem a horizontalizar, junto à comunidade em geral, no momento seguinte e no subseqüente, o conhecimento obtido com a reflexão contida nos trabalhos educativos, numa ação dinâmica.

A metodologia orientada ao município, agente executor do programa, e utilizada no planejamento das práticas desenvolvidas, teve como premissa a integração das políticas públicas de desenvolvimento urbano com as de meio ambiente, saúde e educação. Assim, no âmbito da atuação técnica social da Caixa, foram incentivados a articulação de contatos, reuniões e encaminhamentos para um trabalho em parceria, envolvendo a Secretaria de Promoção Social, a Secretaria de Saúde, a Secretaria de Educação Municipal e empresa contratada pelo município para promover o curso de capacitação de reeditores de EA. A primeira, além da responsabilidade pela articulação dos parceiros, trabalhou o cadastro e a mobilização dos catadores; a segunda, os agentes de saúde; e a terceira, todo o corpo docente das escolas públicas e privadas do município. Já a empresa contratada, ministrou os cursos e oficinas ao público-alvo escolhido: professores da rede pública, agentes de saúde e catadores de materiais recicláveis.

A utilização de canais plurais junto à população para a efetivação das ações socioeducativas num projeto de EA, nos PDU, também se configura como estratégia que favorece resultados positivos concretos. Nesse sentido, a escola passa a ser uma parceira ideal, considerada espaço plural e educativo, propenso para se realizar um trabalho que vise à cooperação com o professor na sua formação como multiplicador/reeditor de conteúdos vinculados à temática ambiental e na formação do aluno que, por sua vez, também desempenha um papel de multiplicador junto à família e à comunidade em geral (VIEIRA; PRADO FILHO, 2004).

Nessa abordagem, Medina lança luz sobre essa proposta de capacitação ao apresentar uma metodologia participativa de formação de recursos humanos, o método Propacc (Proposta de Participação/Ação para a Construção do Conhecimento), em parte, elaborada em bases epistemológicas do construtivismo. Essa metodologia consiste na formação de multiplicadores em EA, formal e não-formal, e possui caráter flexível que permite múltiplas adaptações aos diferentes públicos e objetivos (MININNI-MEDINA, 2001, p.11-42). 


\section{Resultados e discussões}

O estudo demonstrou as dificuldades naturais de um município que, como outros no país, ao desenvolver projetos elaborados por consultorias, com excelentes propostas que atendem aos editais, não possuem capacidade técnica instalada para a gestão e desenvolvimento das ações propostas, sendo a concepção das mesmas alheias à inteligência do município, entendida como a experiência e o conhecimento adquiridos e capazes de serem utilizados na execução do projeto.

Analisando o aspecto da EA, os resultados esperados se voltam para a perspectiva de obter para o município a formação de pessoas qualificadas para o trabalho de disseminação de conhecimentos ambientais, além de desenvolver ações de EA que serviriam de esteio para a sustentabilidade do programa por meio da gestão compartilhada dos resíduos urbanos.

Tais ações, além de sensibilizar, pretendem contribuir para a mudança de hábitos do morador do município e para a sua participação nos processos decisórios e na aplicação dos recursos públicos. Também pretendem formar cidadãos sabedores de seus direitos e deveres, do seu papel fundamental na busca de soluções e no desenvolvimento de ações que visem à sustentabilidade socioambiental.

Os resultados alcançados na experiência que ilustra este artigo podem ser verificados nas diversas ações realizadas e nos impactos percebidos durante a execução do PGIRS, como: a implementação do Fórum do Lixo e Cidadania, com a pretensão de ser espaço de discussões e busca de soluções para as questões ambientais; a sensibilização dos gestores do município, com resultados práticos na contratação de pessoal técnico qualificado para a Diretoria Municipal do Meio Ambiente e outro para a gerência técnica do aterro sanitário e a designação de assistente social como responsável técnica do projeto socioeducativo; a compreensão dos catadores de materiais recicláveis sobre seu papel na preservação do meio ambiente, verificados pelos seus depoimentos; a adesão dos munícipes ao acondicionamento seletivo do lixo, nas áreas piloto da coleta seletiva; a ação dos agentes de saúde do Programa de Saúde da Família, atuando como multiplicadores de informações junto à população; e a divulgação e o debate estabelecidos pelos meios de comunicação com relação às questões ambientais e sobre as responsabilidades do cidadão.

Outro ganho importante foi a adequada prioridade na aplicação das sobras de recursos financeiros alocados para o projeto, advindos da diferença entre os custos inicialmente apresentados e os aprovados após análise, os quais foram utilizados: na recuperação de áreas degradadas (ação que aconteceria somente com recursos a serem obtidos posteriormente); na construção de um galpão de recebimento de embalagens vazias de agrotóxicos utilizados no município e na região do entorno e a construção de área de apoio às atividades de coleta do catador no aterro.

Os resultados da EA desenvolvida foram obtidos com maior ênfase na comunidade escolar, tendo repercussão em outros segmentos. Foram promovidas no âmbito do trabalho social, especificamente de EA, diversas ações, tais como: curso de formação de reeditores de EA "Educar para a Sustentabilidade", envolvendo 130 professores da rede pública escolar de ensino; realização de quatro fóruns Lixo e Cidadania; reuniões dos parceiros para exposição do andamento das obras e trabalho educativo; oficina de EA com os catadores de materiais recicláveis e com os agentes de saúde; dois encontros de capacitação, sensibilizando os trabalhadores da limpeza urbana quanto à coleta seletiva e quanto à segurança no trabalho; campanha e distribuição de cartilhas sobre a coleta seletiva para munícipes, com envolvimento da comunidade escolar e agentes de saúde; projetos de EA nas escolas; criação da Associação dos Catadores de Materiais Recicláveis de Quirinópolis; e criação de uma fundação voltada para ações ambientais no município.

Ao analisar os resultados alcançados e refletindo sobre os avanços obtidos e as dificuldades verificadas, fica evidente a constatação de que a EA pode ser considerada decisiva para o alcance dos objetivos do PGIRS. É um componente estreitamente vinculado ao sucesso do programa no alcance dos seus objetivos, uma vez que deve permear todo o processo de elaboração da proposta de implementação e avaliação dos projetos que fazem parte do programa. 
Os resultados do programa podem alcançar mais efetividade na medida da ação e fiscalização, individual e coletiva, dos munícipes em parceria com a administração pública na gestão integrada dos resíduos sólidos urbanos.

Um intenso trabalho de EA deveria anteceder as diversas fases do programa. Inicialmente, na mobilização das entidades parceiras (requisito para a apresentação da proposta), posteriormente, na permanência dessas entidades em torno da execução do programa, por meio de reuniões e fóruns que privilegiem a participação da comunidade organizada para a gestão dos resíduos sólidos urbanos. Essas parcerias configuram-se como componente fundamental a ser envolvido nas ações socioeducativas inerentes à EA. Diferente dessa proposta, os editais do programa pressupõem somente o envolvimento dos parceiros no acompanhamento da obra, com exigência de emissão periódica de relatórios dessa atividade.

Outro segmento onde se prevê a qualificação profissional para a gestão e operação dos resíduos é o dos gestores e servidores públicos da área de resíduos, que na maioria dos casos tampouco são trabalhados na perspectiva da EA. Essa qualificação, quando proposta, está voltada mais para a segurança do trabalho e a operação do sistema em si, carecendo de um trabalho voltado para a elevação da consciência ambiental desses cidadãos.

Uma parcela importante da população, pela sua importância no processo de gestão dos resíduos, é a de catadores de materiais recicláveis, que com seu trabalho de obtenção de renda para a sobrevivência, por meio da seleção e comercialização dos resíduos, contribuem para a diminuição da pressão exercida pelo lixo urbano no meio ambiente, ampliando a vida útil do aterro sanitário como benefícios diretos de seu trabalho.

O principal fator que impulsionou a criação do Programa Lixo e Cidadania foi a verificação das precárias condições de trabalho desse segmento da população. O programa desenvolve suas ações por meio do Fórum Nacional Lixo e Cidadania, criado no ano de 1998 e coordenado por entidades governamentais e nãogovernamentais que se preocupam com aqueles que sobrevivem dos lixões, principalmente as crianças. Entre essas entidades estão o Fundo das Nações Unidas para a Infância (Unicef), o Ministério do Meio Ambiente (MMA), o Ministério Público Federal (MPF), o Ministério das Cidades (Mcidades), a Fundação Nacional da Saúde (Funasa), a Caixa Econômica Federal e a ONG Água e Vida - Centro de Estudos de Saneamento Ambiental. $\mathrm{O}$ fórum já foi implantado em alguns estados e municípios, e seus objetivos estão voltados para o favorecimento da discussão e estímulo ao desenvolvimento de projetos e ações para erradicar o trabalho infantil nos lixões, além de possibilitar o fim dos lixões e a geração de renda para as famílias dos catadores.

O trabalho desenvolvido pelos fóruns e movimentos organizados desse segmento no Brasil visa ao reconhecimento dos catadores pela sociedade como categoria profissional. Uma das conquistas foi o reconhecimento da atividade de catador pelo Ministério do Trabalho e Emprego, na Classificação Brasileira de Ocupações (BRASIL, 2002), com código 5192-05, apresentando a definição e a descrição das atividades e competências pessoais requeridas. Esse é um primeiro passo para o reconhecimento da profissão e sinaliza melhoria no aspecto da concessão de crédito para investimento na atividade.

A atribuição sumária dessa ocupação é "a coleta, seleção e comercialização de materiais recicláveis, tais como papel, papelão, vidro, materiais ferrosos e não ferrosos e outros materiais reutilizáveis." (BRASIL, 2002).

A inclusão social dos catadores vem a ser uma prioridade por dois motivos cruciais: o social, uma vez que o aumento dos catadores nos centros urbanos, numa situação de exclusão social, precariedade e insalubridade no trabalho, passa a significar um problema grave não só para a administração local como também para a União; e o econômico, a partir do momento que o lixo passa a ser percebido como uma mercadoria, isto é, tem um valor comercial, é uma fonte de renda.

Portanto, de uma condição de excluídos, os catadores passam a ser parceiros, pois são "agentes ambientais" trabalhando na limpeza urbana e contribuindo para o equilíbrio e a sustentabilidade ambiental. Diante disso, os órgãos municipais passam a assumir responsabilidades tais como:

Articulação entre diferentes atores envolvidos no processo; abertura de diálogo com os catadores; incentivos aos mercados de recicláveis; realização de campanhas de sensibilização social; disponibili- 
zação de infra-estruturas para os programas e elaboração de instrumentos jurídicos (ROMANI, 2004, p.13).

A totalidade da população urbana pode ser considerada beneficiária do sistema de disposição e tratamento de resíduos. Essa população é parceira potencial na busca da sustentabilidade do sistema implantado, tendo como principal contribuição a disposição adequada do lixo doméstico previamente selecionado como lixo seco e lixo molhado/úmido. Tais ações contribuirão para o trabalho do catador se tornar digno e salubre, facilitando a separação, evitando a contaminação e aumentando o grau de aproveitamento com vista à reciclagem do material gerado pelo descarte da população.

\section{Educação ambiental como pressuposto para a sustentabilidade do PGIRS}

A EA, entendida como instrumento da construção de uma cidadania crítica e responsável (MININNIMEDINA, 2001, p.9), pode se tornar um elemento indispensável no enfrentamento dos desafios ambientais que se impõem ao poder público e aos cidadãos na atualidade. A metodologia de realização de projetos de EA, junto aos diferentes segmentos sociais, que privilegie a real participação comunitária nas ações empreendidas, torna-se instrumento do despertar da consciência ambiental dos indivíduos.

O destinatário da EA não-formal é toda a população: os empresários, os trabalhadores em geral, os políticos e as comunidades com seus diversos atores sociais, organizados ou não em grupos afins.

Integram-se à definição de atores sociais locais aqueles que têm capacidade e unicidade de ação sobre o desenvolvimento e o bem-estar da comunidade. "Desse modo, constituem-se em atores locais todas as pessoas e instituições que, no campo político, econômico, social e cultural, são sujeitos do desenvolvimento local." (IBAM, 1999).

$\mathrm{O}$ ambiente de ensino formal, qual seja, as escolas, universidades e entidades de ensino, constituem canais eficientes para o desenvolvimento de um projeto de EA, com ações socioeducativas voltadas para o fomento à participação da comunidade e com caráter educativo capaz de gerar uma rede de atitudes transformadoras do modo atual de vida daquela população, na perspectiva da cidadania.

A educação formal conta com princípios norteadores, elaborados no âmbito do Ministério da Educação, para o desenvolvimento da temática ambiental junto à comunidade escolar, como os temas transversais dos Parâmetros Curriculares Nacionais (PCN), que apresentam como objetivo, desde a sua criação, "contribuir para a formação de cidadãos conscientes, aptos para decidirem e atuarem na realidade socioambiental de um modo comprometido com a vida, com o bem-estar de cada um e da sociedade, local e global." (BRASIL, 1997, p.29).

A implantação de uma agenda ambiental em espaços definidos, quer seja na escola, nas repartições públicas, nas empresas ou nos bairros, contribui para a consolidação da Agenda 21, que pode se caracterizar como componente de um plano de desenvolvimento sustentável de um município, exigindo uma prática de EA pautada pela participação comunitária.

A capacitação para a formação de multiplicadores em EA é uma metodologia que contribui para a implementação de projetos, onde se pretende o envolvimento de diferentes segmentos sociais. Poderá ser direcionada a diversos grupos, como aqueles que têm sua atuação orientada para um público definido, como é o caso de professores, lideranças comunitárias, agentes de saúde, políticos e representantes de entidades, entre outros. Tais grupos são importantes no processo, pois além de contar com um público-alvo para repassarem conteúdos, valores e atitudes adquiridas, atuam direta ou indiretamente na tomada de decisões.

É pelo processo de aprendizagem que vão sendo construídos novos valores ambientais e uma nova ética política que redefinem os estilos de vida, na perspectiva da construção de novos modelos econômicos. Uma aprendizagem que relacione homem, natureza e universo numa perspectiva holística, que busque atuar de forma democrática com base no diálogo, na solidariedade, igualdade e respeito. Um processo que valorize "as diversas culturas, etnias, e sociedades, principalmente aquelas dos povos tradicionais." (LEONARDI, 2001, p.394). 
Nesse processo de aprendizagem se formam gestores, que na construção e apropriação de conceitos, sob uma matriz de racionalidades diferenciadas com base na diversidade cultural, ressignificam os princípios de racionalidade ambiental. Estes passam a fazer parte da vida de cada pessoa e comunidade, capacitando-as para a condução da transição para um futuro democrático e sustentável (LEFF, 2001, p.246).

\section{Propostas para a melhoria do desempenho dos PGIRS}

Defende-se aqui, que é possível aperfeiçoar os resultados alcançados com a implementação de um programa de gestão integrada dos resíduos sólidos urbanos. Para isso é decisiva a ação política dos agentes executores na democratização da gestão com o envolvimento dos munícipes, utilizando-se como principal estratégia a educação ambiental em todos os níveis.

Considerando a possibilidade de ampliar os resultados alcançados com a implementação do PGIRS no município em pauta, e ainda como subsídio à intervenção em qualquer que seja o município, são apontadas a seguir algumas propostas de revisão da metodologia de execução do PGIRS, entre elas:

- realizar, num momento anterior à elaboração da proposta para enquadramento no programa, um diagnóstico participativo sobre o estado da gestão dos resíduos sólidos do município nas diversas entidades locais, buscando identificar os problemas e as possíveis soluções;

- promover, a exemplo das orientações do Ministério das Cidades para a elaboração do Plano Diretor Municipal (BRASIL, 2004), como ação anterior à execução do programa, a capacitação da comunidade local para a participação no processo decisório, com ações voltadas para a EA e gestão dos resíduos sólidos urbanos. O público-alvo seria, especialmente, os gestores públicos; os técnicos e funcionários da administração pública, direta e indiretamente envolvidos na implementação do programa; os representantes das entidades locais; os catadores de material reciclável e o pessoal vinculado à limpeza urbana. Essas ações poderiam se dar em oficinas e seminários, visando à informação e sensibilização, na perspectiva de sua adesão como verdadeiros parceiros na consecução da proposta e na gestão continuada dos RSU. Para tanto, tal ação deveria estar prevista no programa;

- promover por meio dos consultores e especialistas contratados, a capacitação técnica da equipe local que participa da execução do programa, visando à transferência eficaz de conhecimento, especialmente, dos técnicos das áreas de engenharia, arquitetura, jurídica e social, assegurando a aquisição de expertise;

- buscar formas de assegurar, durante e após a fase de execução do programa, que o Fórum Municipal do Lixo e Cidadania seja um espaço democrático, não só informativo, mas propositivo e deliberativo, aberto a todos os parceiros e demais entidades que queiram contribuir com discussões, proposições e encaminhamentos das ações, respeitadas as possibilidades técnicas;

- constituir uma comissão paritária e representativa do poder público e da sociedade, para o acompanhamento da execução das ações integradas de obras físicas, projetos socioeducativos e planos inerentes ao PGIRS;

- criar espaços para desenvolvimento de projetos participativos, especialmente, nas temáticas de RSU, como centros de educação ambiental, com envolvimento da população, principalmente, das crianças e adolescentes da comunidade escolar; $\mathrm{e}$

- desenvolver projetos educativos continuados de visitação à área do aterro, dando visibilidade a todo o processo que envolve os RSU, desde a geração até a disposição final no aterro, bem como dos serviços de limpeza urbana, de forma continuada, buscando envolver o cidadão como integrante e co-responsável pelo processo; entre outras.

Experiências bem-sucedidas têm se destacado no âmbito de projetos de EA vinculados a PDU. Um único exemplo é aqui citado, devido a sua abrangência e a sua fácil replicabilidade, respeitadas as proporções possíveis. Trata-se de uma prática implementada pela Companhia de Saneamento do Estado de Goiás (Saneago), na implantação da Estação de Tratamento de Esgotos (ETE) de Goiânia, capital do estado de Goiás. Nesse programa houve o repasse de recursos do OGU e o acompanhamento da equipe técnica multidisciplinar da Caixa. 
Alguns dos resultados do trabalho socioeducativo desenvolvido nesse programa estão registrados nos arquivos de acompanhamento da Caixa e em diversas publicações de artigos técnicos, em boletins e no sítio da companhia de saneamento de Goiás, executora do programa, no link Projeto Social ETE Goiânia, (www.saneago.com.br).

Nesse projeto, aconteceram várias ações voltadas para a inclusão social da população ribeirinha, de baixa renda, moradora das margens dos córregos onde foram implantados os interceptores das redes de esgotos. Das ações do projeto social, o maior destaque está no projeto de EA com a construção de uma escolinha de saneamento, desde o início da obra física da ETE. Essa ação foi precedida de diversos encontros das equipes técnicas da Saneago e da Caixa, pela qualificação técnica de profissionais do quadro e pelo envolvimento de todos os níveis decisórios da companhia, a qual aportou recursos próprios, além daqueles previstos no programa, para o trabalho socioeducativo.

Os principais objetivos da escolinha de Saneamento Jornalista Washington Novaes é transmitir conhecimentos sobre recursos hídricos (cuidados, preocupação, preservação, utilização e manejo dos mesmos); informar o público sobre a ameaça da escassez de água e sobre o processo de abastecimento; conscientizar sobre a necessidade da preservação das áreas verdes (matas ciliares, vegetação nativa etc.); demonstrar o processo de coleta e tratamento dos esgotos sanitários (como é feito, quais as técnicas utilizadas); promover o conhecimento de doenças que podem ser transmitidas pela água não tratada (doenças de veiculação hídrica); instruir o público sobre o uso adequado das redes coletoras de esgotos e relacionar os transtornos que possam advir do uso inadequado das redes (SANEAGO, 2006).

A escolinha tem como principal público a comunidade escolar. A maior parte do público são as escolas do ensino fundamental (não excluindo as do ensino médio e as instituições de ensino superior). Possui capacidade para receber até 100 alunos por seção, sendo agendadas visitas para todos os dias letivos, durante o ano todo, tendo como suporte permanente dois ônibus que buscam os alunos nas escolas, inclusive, em outras cidades da Região Metropolitana de Goiânia. Em algumas temporadas, a escolinha se desloca com seus profissionais para o interior de estado, levando o trabalho para outros municípios.

O programa consiste em proporcionar aos alunos, professores e diretores noções básicas de saneamento através de palestras, apresentação de filmes e peças teatrais infantis interativas, relacionados à proteção de mananciais, sistema de tratamento de água e coleta e tratamento de esgoto sanitário. A programação segue com a visita à maquete da ETE e o passeio de trenzinho por toda a área da ETE (tratamento, laboratório, piscicultura etc.). No retorno, o lanche e o plantio de mudas de árvores do cerrado pelos próprios alunos, fato que é sempre documentado. Ao final do evento, são distribuídas carteirinhas de fiscal do meio ambiente, além de cartilhas (abrangendo turmas de $1^{\underline{a}}$ a $3^{\underline{a}}$ séries ou de $4^{\underline{a}}$ a $8^{\underline{a}}$ séries) à escola visitante, para serem trabalhadas de forma multidisciplinar com os alunos.

Periodicamente, são realizados pela escolinha os concursos de redação, desenhos na temática de água e esgotos, com participação de todas as escolas visitantes. A premiação acontece em eventos com a presença de autoridades, da imprensa e da sociedade em geral, dando visibilidade ao trabalho desenvolvido, valorizando o conhecimento e a produção dos alunos (Id, 2006).

Além das ações citadas houve, no projeto social, visitações técnicas com orientação sobre a correta destinação dos esgotos domésticos para 11.000 imóveis, com monitoramento e acompanhamento daqueles com instalações irregulares, com reversão da maioria dos casos.

Alguns números são mostrados como indicadores de resultado das ações desenvolvidas pela escolinha da ETE, todas com a participação da comunidade, conforme relatório da Saneago de março de 2006, sendo a maioria escolas, e algumas entidades filantrópicas, grupos de idosos, associações e universidades:

- 138.440 visitantes entre crianças, adolescentes e adultos;

- 139.536 lanches distribuídos;

- 3.486 viagens de ônibus efetuadas;

- 1.316 viagens de trenzinho efetuadas; e 
- 14.589 árvores plantadas.

\section{Considerações finais}

O debate em torno da criação de uma política nacional de resíduos sólidos passa pela discussão de diversas questões, sendo a educação ambiental um componente indispensável.

Ampliar a sensibilização dos munícipes para a sua proposição na gestão dos resíduos sólidos e das questões ambientais em geral ainda é um desafio em Quirinópolis, como o é na maioria dos municípios brasileiros.

Percebe-se, como observado nos demais municípios que desenvolvem o PGIRS, que há a necessidade de fomento ao desenvolvimento institucional da administração pública municipal para a gestão adequada dos resíduos urbanos, inclusive para garantir a continuidade das ações implantadas por um programa dessa natureza. Uma pesquisa de avaliação no município objeto deste estudo, realizada no âmbito de uma tese de doutorado (VIEIRA, 2006), pôde constatar que muitas conquistas do Programa se perderam, como a coleta seletiva, principal ação de apoio do poder público à organização dos catadores.

A necessidade de qualificação dos gestores municipais e do corpo técnico local é visível e se justifica na medida em que estes possam buscar a solução dos problemas relacionados aos resíduos sólidos urbanos, de forma integrada e participativa, na comunidade local, por meio de maiores conhecimentos adquiridos.

Tais conhecimentos abrangeriam informações sobre a questão ambiental relacionada ao lixo, gerados a partir de ações voltadas à educação ambiental e cursos de capacitação para a gestão dos resíduos sólidos e para a operação de um sistema adequado que envolveria desde a disposição dos resíduos (domésticos, comerciais, industriais, de saúde e outros) até a sua destinação ao aterro sanitário. Entre as diversas fases, podem ser citadas a triagem e separação dos resíduos recicláveis, com envolvimento dos munícipes na disposição adequada, dos servidores da limpeza urbana na coleta e dos catadores na separação final do lixo gerado pela população, contribuindo para a sustentabilidade do programa, entendendo que:

Sustentabilidade implica sistemas implantados com funcionalidade, com tecnologias que previnam os impactos negativos sobre o meio ambiente, atendendo às necessidades da população para quem foram concebidos, com resultados positivos na sua implementação. [...] requer práticas que possibilitem mudanças significativas nos padrões de vida dessa população, não só no aspecto físico, como e principalmente no social, incorporando melhorias nas condições de saúde, moradia, renda, educação, cultura, e a ampliação da consciência ambiental, denotando indivíduos informados, participantes na gestão ambiental urbana, com elevada auto-estima, cônscios de seu direito ao exercício da cidadania plena. (VIEIRA, 2002)

Assim, em programas com um rol de ações que visam solucionar os problemas ambientais urbanos, especificamente de resíduos sólidos como o PGIRS, a percepção desses problemas e o exercício da reflexão coletiva, no âmbito da administração pública e da sociedade organizada, poderia se dar como um projeto específico anteriormente à contratação de recursos para as obras físicas, e perdurar com maior ênfase na fase de implantação das obras e dos demais projetos, por meio de um intenso trabalho de educação ambiental, concorrendo para a efetividade dos resultados alcançados e para a sustentabilidade socioambiental do programa. 


\section{Referências}

ANDRADE, S. A. Bases filosóficas-científicas do pensamento ambiental. In: LEITE, A. L. T.; MEDINA, N. M. Questões ambientais, conceitos, história, problemas e alternativas. 2.ed. Brasilia, DF: MMA, 2001. 5v.

BECKER, D. F. Sustentabilidade: um novo (velho) paradigma de desenvolvimento regional. In: BECKER, D. F. (Org.). Desenvolvimento sustentável - necessidade e/ou possibilidade? Santa Cruz do Sul: Edunisc, 1999.

BRASIL. Ministério da Educação. Secretaria de Educação Fundamental. Parâmetros Curriculares Nacionais: meio ambiente, saúde, temas transversais. Brasilia, DF, 1997. 10v. v.9.

Ministério do Meio Ambiente. Principais resultados do Programa Brasil Joga Limpo. Ministério do Meio Ambiente. Secretaria da Qualidade Ambiental. Disponivel em: <http://www.mma.gov.br/port/sqa/brasilj//acoes/resultados.html>. Acesso em: 18 abr. 2004.

Ministério das Cidades. Plano diretor participativo: guia para a elaboração pelos municípios e cidadãos. Brasilia, DF, 2004.

Ministério do Meio Ambiente. Fundo Nacional do Meio Ambiente (FNMA). Edital n- 5/2001. Fomento a projetos de gestão integrada de resíduos sólidos urbanos. Brasilia, DF, 2001a.

Ministério do Meio Ambiente. Fundo Nacional do Meio Ambiente (FNMA). Edital no 12/2001. Fomento a projetos de gestão integrada de resíduos sólidos urbanos. Brasilia, DF, 2001 b.

Ministério do Trabalho e Emprego. Classificação Brasileira de Ocupações. CBO 94 - Portaria no 397, de 9 de outubro de 2002. Disponivel em: <http://www.mtecbo.gov.br/indexFaqs.asp>. Acesso em: 5 maio 2006.

CAIXA ECONÔMICA FEDERAL. História, Missão e Visão de Futuro. Disponivel em: <http://www.caixa. gov.br/acaixa/asp/historia_e_missao.asp> Acesso em: 23 ago. 2005.

FIOCRUZ. Lasat/Nesc/CPqAM/Fiocruz. Análise dos investimentos em saneamento no Brasil no período de 1996-2000. Recife, 2002.

IBAM. Texto de fundamentação. Estratégia Caixa do município. Curso de Desenvolvimento Sustentado. Rio de Janeiro: Ibam/CEF, 1999.

LEFF, E. Saber ambiental: sustentabilidade, racionalidade, complexidade e poder. Petrópolis, RJ: Vozes, 2001.

LEONARDI, M. L. A. A educação ambiental como um dos instrumentos de superação da insustentabilidade da sociedade atual. In: CAVALCANTI, C (Org.). Meio ambiente, desenvolvimento sustentável e políticas públicas. 3.ed. São Paulo: Cortez; Recife: Fundação Joaquim Nabuco, 2001.

MININNI-MEDINA N. A educação ambiental na educação formal. In: LEITE, A. L. T. A.; MEDINA, N. M. Educação ambiental: a educação e educação ambiental I. 2.ed. Brasilia, DF: MMA, 2001. $5 \mathrm{v}$.

ROMANI, Andréa Pitanguy de. 0 Poder público Municipal e as Organizações de Catadores. Rio de janeiro. IBAM/DUMA/CAIXA, 2004.

QUINTAS, J. S. Gestão ambiental. In: LEITE, A. L T. A.; MEDINA, N. M. Educação ambiental: a educação e educação ambiental I. 2.ed. Brasília, DF: MMA, 2001. 5v.

SANEAGO. Projeto Social ETE Goiânia. Escolinha AbcS: Escolinha de Saneamento Jornalista Washington Novaes. Disponivel em: $<$ http://www.saneago.com.br>. Acesso em: 29 abr. 2006.

VIEIRA, J. E. G. Educação para a sustentabilidade: um pressuposto da participação comunitária na gestão ambiental nas cidades. Serviço Social e Sociedade, São Paulo, Cortez, Ano XXIII, n.72, p.62-70, 2002.

; Modelo de avaliação de impactos socioambientais de programas de resíduos sólidos urbanos. Tese (Doutorado em Ciências Ambientais) - Universidade Federal de Goiás. Goiânia, 2006.

;PRADO FILHO, O. B. A educação ambiental no Pro-Infra. In: SIMPÓSIO LUSO-BRASILEIRO DE ENGENHARIA SANITÁRIA E AMBIENTAL, 11, 2004. Anais... Natal, RN, 2004. 